\title{
Avaliação da qualidade do colostro e transferência de imunidade passiva em animais mestiços Holandês Zebu
}

\author{
[Colostrum quality evaluation and passive immunity transfer in crossbred Holstein Zebu cattle] \\ B.F. Silper ${ }^{1}$, S.G. Coelho ${ }^{2 *}$, M.M.F. Madeira ${ }^{3}$, J.R.M. Ruas ${ }^{4}$, A.M.Q. Lana $^{2}$, \\ R.B. Reis $^{2}$, H.M. Saturnino ${ }^{2}$ \\ ${ }^{1}$ Aluna de pós-graduação - Escola de Veterinária - UFMG - Belo Horizonte, MG \\ ${ }^{2}$ Escola de Veterinária, UFMG - Belo Horizonte, MG. \\ ${ }^{3}$ Alunos de graduação - Escola de Veterinária - UFMG - Belo Horizonte, MG \\ ${ }^{4}$ EPAMIG - Belo Horizonte, MG
}

\section{RESUMO}

O objetivo desta pesquisa foi avaliar a qualidade do colostro de vacas mestiças Holandês Zebu e a transferência de imunidade a seus bezerros. Efeitos de ordem de parto, sexo do bezerro, estação do ano e grupo genético foram estudados em vacas distribuídas em quatro grupos genéticos. Amostras de sangue dos bezerros foram coletadas aos três dias de vida. Foi avaliada a concentração de proteína total no soro (PT) por refratometria e espectrofotometria. As amostras de colostro apresentaram alta qualidade, com concentração média de Ig de $78,5 \mathrm{mg} / \mathrm{mL}$. Houve adequada transferência de imunidade passiva, com $88,3 \%$ dos bezerros com PT acima de 5,5g/dL. Não houve efeito de ordem de parto, sexo do bezerro, estação do ano e grupo genético da vaca na qualidade do colostro e na PT $(\mathrm{P}>0,05)$. Vacas $\mathrm{F} 1$ produziram, em média, colostro de alta qualidade e houve sucesso na transferência de imunidade passiva.

Palavras-chave: bezerro, colostrômetro, densidade, imunoglobulina

\begin{abstract}
The objective of this paper was to evaluate crossbred Holstein Zebu cows colostrum quality and passive immunity transfer to their calves. Parity, calf sex, season of the year and cow genetic group effects in both responses were analyzed. Quality (immunoglobulin - Ig - concentration) was measured in colostrum samples of 186 crossbred cows from four different genetic groups with a colostrometer. Calf's blood samples were collected on the third day of life. Serum total protein concentration (PT) was measured through refractometry and spectrophotometry. Colostrum samples were classified as high quality and showed mean Ig concentrations of $78.5 \mathrm{mg} / \mathrm{mL}$. Passive immunity transfer was successful, since $88.3 \%$ of calves had PT higher than $5.5 \mathrm{~g} / \mathrm{dL}$. There was no effect of parity, calf sex, season of the year or cow genetic group in colostrum quality or serum total protein concentration $(P>0.05)$. Crossbred Holstein Zebu cows produced high quality colostrums. There was success in passive immunity transfer to the calves.
\end{abstract}

Keywords: calf, colostrometer, immunoglobulin, specific gravity

\section{INTRODUÇÃO}

A criação de bezerras e novilhas representa parte importante dos custos de sistemas de produção de leite, sendo a saúde destes animais

Recebido em 3 de junho de 2011

Aceito em 29 de dezembro de 2011

*Autor para correspondência (corresponding author)

E-mail: sandra@vet.ufmg.br fundamental para criação eficiente. A transferência de imunidade passiva pelo colostro é essencial para a sobrevivência dos bezerros, já que a placenta dos bovinos, do tipo epitélio-corial, impede a transferência de imunoglobulinas da mãe para o feto. O colostro é 
a primeira secreção produzida pela glândula mamária após o período seco e é fonte de imunoglobulinas, nutrientes, hormônios e fatores de crescimento (Butler, 1971).

O sucesso na transferência de imunidade passiva depende de fatores como concentração de imunoglobulinas no colostro, volume ingerido, intervalo de tempo entre o nascimento e a ingestão, qualidade sanitária do colostro e capacidade de absorção. A qualidade do colostro está relacionada a volume produzido, contato anterior da vaca com patógenos e duração do período seco (Davis e Drackley, 1998). O volume ingerido e o tempo de vida no momento da mamada, assim como a qualidade, podem ser controlados quando o colostro é fornecido por mamadeira ou sonda esofágica. A capacidade absortiva depende de boa condição fisiológica do bezerro ao nascimento. Animais em acidose respiratória ao nascer têm menor capacidade de absorver as imunoglobulinas do colostro nas primeiras 12 horas de vida (Besser et al., 1990). No entanto, Godden (2008) relata que não há diferenças na capacidade absortiva total entre estes bezerros e aqueles normais e afirma que as diferenças observadas em alguns trabalhos devem estar relacionadas ao maior tempo gasto pelo bezerro para levantar e mamar o colostro. A qualidade microbiológica do colostro também é importante, pois bactérias no colostro podem reduzir a absorção intestinal de macromoléculas como as imunoglobulinas (James et al., 1990).

A qualidade do colostro é determinada por sua concentração de imunoglobulinas, principalmente IgG. A mensuração da concentração de IgG pode ser feita diretamente, por imunodifusão radial, ou indiretamente, com o uso do colostrômetro, um hidrômetro desenvolvido por Fleenor e Stott (1980). Este equipamento permite estimar a qualidade do colostro com base na correlação linear entre a concentração de imunoglobulinas e sua densidade. O colostro que contém acima de $49,8 \mathrm{mg} / \mathrm{mL}$ de globulinas é considerado de boa qualidade.

A transferência de imunidade passiva pode ser avaliada pela dosagem de IgG no soro, por imunodifusão radial. Segundo Godden (2008), há falha na transferência de imunidade pelo colostro quando bezerros com 24 a 48 horas de vida têm menos de $10 \mathrm{mg}$ de $\mathrm{IgG} / \mathrm{mL}$ de soro. Outro método que permite esta avaliação é a dosagem de proteínas totais no soro de bezerros com até sete dias de idade. A avaliação de proteína total pode ser feita com uso de refratômetro ou espectrofotômetro (método colorimétrico). A dosagem sérica de proteína total apresenta alta correlação com a concentração de Ig (Naylor e Kronfeld, 1977). Considera-se ingestão suficiente de colostro quando os bezerros apresentam proteínas totais no soro acima de $5,5 \mathrm{~g} / \mathrm{dL}$ (McGuirk, 2003). A qualidade do colostro para animais da raça Holandesa está bem estabelecida na literatura, assim como os fatores relacionados à transferência de imunidade passiva (Davis e Drackley, 1998). No entanto, há poucos relatos sobre animais mestiços.

O objetivo deste trabalho foi avaliar a qualidade do colostro de vacas mestiças Holandês Zebu, a transferência de imunidade das mães para os bezerros e a influência da composição genética, estação do ano do parto e sexo do bezerro na qualidade do colostro e na transferência de imunidade passiva.

\section{MATERIAIS E MÉTODOS}

Todos os procedimentos experimentais foram aprovados pelo Comitê de Ética em Experimentação Animal da Universidade Federal de Minas Gerais (CETEA/UFMG), certificado $n^{\circ}$ $128 / 2007$.

O experimento foi realizado na Fazenda Experimental da Epamig, em Felixlândia, MG, no período de janeiro de 2007 a fevereiro de 2008. Foram avaliadas amostras de colostro de 186 vacas mestiças, sendo 115 vacas Holandês x Gir, 16 Holandês $\mathrm{x}$ Nelore, 31 Holandês $\mathrm{x}$ Guzerá, e 24 Holandês x Zebu, assim denominadas quando a ascendência zebu não era conhecida. Os animais foram alimentados com cana-de-açúcar e silagem de milho no inverno e mantidos em pasto no verão. Durante todo o ano, receberam suplementação de concentrado.

Amostras de colostro foram coletadas por ordenha manual, em volume de $50 \mathrm{~mL}$. Nos partos ocorridos durante o dia, o colostro foi coletado antes da mamada do bezerro. Nos partos noturnos, a coleta foi realizada no dia seguinte, apenas de quartos mamários não mamados. A concentração de imunoglobulinas no colostro foi avaliada à temperatura ambiente, com a 
utilização de colostrômetro, de acordo com escala proposta por Fleenor e Stott (1980): até $21,8 \mathrm{mg} / \mathrm{mL}$, colostro de baixa qualidade; de 22 a $49,8 \mathrm{mg} / \mathrm{mL}$, qualidade intermediária; e acima desse valor, colostro de alta qualidade.

Para avaliar a transferência de imunidade passiva, foram coletadas amostras de sangue $(5 \mathrm{~mL})$ dos bezerros. As amostras foram coletadas aos três dias de vida do bezerro, em tubos sem anticoagulante. Após centrifugação, a 5000 RPM, por cinco minutos, o soro foi estocado em ependorf e congelado. A dosagem de proteína total foi realizada em refratômetro e também pelo método colorimétrico - reação com sulfato de cobre e leitura em espectrofotômetro.

$\mathrm{O}$ experimento foi montado seguindo o delineamento estatístico inteiramente ao acaso. Foram realizadas análise estatística descritiva, de variância e do qui-quadrado, considerando-se composição genética, sexo do bezerro e estação do ano sobre a concentração de imunoglobulinas no colostro e sobre a dosagem sérica de proteína total dos bezerros. $\mathrm{O}$ efeito de ordem de parto foi avaliado apenas sobre a qualidade do colostro.

\section{RESULTADOS E DISCUSSÃO}

A concentração média de imunoglobulinas (Ig) observada foi $78,5 \mathrm{mg} / \mathrm{mL}$, o que corresponde a colostro de alta qualidade, sendo a concentração média de $\mathrm{Ig}$ de $66,7 \mathrm{mg}$ de $\mathrm{IgG} / \mathrm{mL}$, pois, segundo Davis e Drackley (1998), 85\% das imunoglobulinas do colostro são $\mathrm{IgG}$. $\mathrm{O}$ valor médio obtido é superior à média relatada para a raça Holandesa por Pritchett et al. (1991), igual a $48,2 \mathrm{mg}$ IgG1/mL, e por Quigley et al. (1993), para a raça Jersey $(69,9 \mathrm{mg} \mathrm{Ig} / \mathrm{mL})$. A maior concentração de imunoglobulinas no colostro de vacas mestiças pode ser devido ao menor volume produzido e à idade ao primeiro parto mais tardia, permitindo exposição a uma variedade maior de antígenos. Não houve diferença $(\mathrm{P}>0,05)$ entre os grupos genéticos quanto à concentração de imunoglobulinas no colostro (Tab. 1). A ausência de diferença pode ser devido ao fato de os animais terem sido criados todos em mesma condição de manejo com os mesmos desafios imunológicos, e ao pequeno volume de colostro produzido em todos os grupos genéticos. Do total de amostras analisadas, $87,6 \%$ apresentaram alta qualidade, segundo a classificação de Fleenor e Stott (1980).

Não houve efeito de sexo do bezerro, ordem de parto ou estação do ano sobre a qualidade do colostro (P>0,05). Quigley et al. (1994) e Pritchett et al. (1991) observaram diferenças na concentração de imunoglobulinas no colostro de vacas de diferentes ordens de parto. Estes autores relatam maior concentração de IgG em vacas com três ou mais crias. Vacas mestiças HZ podem apresentar colostro de alta qualidade, inclusive no primeiro parto, por este ocorrer, em média, em idade mais tardia do que em animais puros de raças europeias, e assim haver poucas mudanças nos partos seguintes. Gulliksen et al. (2007) observaram menor concentração de IgG no colostro de vacas que pariram no inverno em relação às demais estações do ano em vacas leiteiras da raça Norwegian. Os autores atribuíram essa diferença às mudanças bruscas no clima, relacionadas a estações do ano bem pronunciadas, que levam a variações na temperatura ambiente, dieta e incidência de doenças. As variações climáticas ao longo do ano são menores na região onde o presente trabalho foi realizado, o que reduz este possível efeito na concentração de imunoglobulinas no colostro.

Tabela 1. Concentração média e desvio-padrão de imunoglobulinas do colostro nos diferentes grupos genéticos

\begin{tabular}{lc}
\hline Grupo genético & $\begin{array}{c}\text { Concentração de } \\
\text { imunoglobulinas } \\
(\mathrm{mg} / \mathrm{mL}) *\end{array}$ \\
\hline Holandês x Gir & $78,6 \pm 27,2$ \\
Holandês x Nelore & $66,9 \pm 28,0$ \\
Holandês x Guzerá & $86,1 \pm 22,8$ \\
Holandês x Zebu & $76,7 \pm 18,1$ \\
\hline
\end{tabular}

*As médias não diferiram estatisticamente pelo teste de Fisher $(\mathrm{P}>0,05)$.

$\mathrm{CV}=32,4 \%$.

A concentração média de imunoglobulinas observada no soro dos bezerros aos três dias de vida foi $7 \mathrm{~g} / \mathrm{dL}$, quando medida por espectrofotômetro, e $10,1 \mathrm{~g} / \mathrm{dL}$ por refratômetro (Tab. 2). A correlação entre os dois métodos para mensurar a proteína total sérica foi mediana, igual a $0,6 \quad(\mathrm{P}<0,01)$. Dos bezerros, 88,3\% apresentaram concentração sérica de proteína total acima de $5,5 \mathrm{~g} / \mathrm{dL}$, o que indica que eles foram, em média, bem colostrados. Segundo McGuirk (2003), há problemas na transferência 
de imunidade passiva em rebanhos, com mais de $20 \%$ dos bezerros com dosagem sérica de proteína total menor que $5,5 \mathrm{~g} / \mathrm{dL}$ até os sete dias de idade. Apesar de os bezerros terem mamado o colostro sem acompanhamento, houve adequada transferência de imunidade passiva. Isso pode estar relacionado à alta qualidade do colostro, ao fato de os bezerros serem leves e as mães, vacas F1 Holandês Zebu, possuírem úbere com inserção mais alta, o que facilitaria a ingestão do colostro. Além disso, a criação em piquetes com baixa densidade animal permite úberes e tetos mais limpos e menor contagem bacteriana do colostro facilitando a transferência de imunidade passiva.

Não houve efeito de composição genotípica da vaca, estação do ano ou sexo do bezerro na concentração sérica de proteína total aos três dias de vida $(\mathrm{P}>0,05)$. Donovan et al. (1986) observaram efeitos de mês de nascimento e temperatura máxima diária na concentração sérica de proteína total de bezerros Holandeses, mas não observaram efeito de sexo nesta medida. Stott et al. (1975) relataram menor concentração de $\mathrm{IgG}$, medida aos dois dias de vida, no soro em bezerros sob estresse térmico, se comparados àqueles em condições de conforto térmico. A ausência de efeito da estação do ano na dosagem de proteína total dos bezerros neste experimento pode ser devido às pequenas variações climáticas da região ao longo do ano. Ainda, animais mestiços HZ são mais adaptados ao calor, se comparados aos bezerros Holandeses utilizados nos trabalhos citados acima.

Tabela 2. Dosagem média e desvio-padrão de proteína total de bezerros F2 aos três dias de vida por espectrofotometria e refratometria

\begin{tabular}{lcc}
\multicolumn{2}{c}{ Grupo genético (vaca F1) } & \multicolumn{2}{c}{ Proteína total $(\mathrm{g} / \mathrm{dL})$} \\
\cline { 2 - 3 } & Espectrofotometria & Refratometria \\
\hline Holandês x Gir & $7,0 \pm 1,4$ & $10,1 \pm 1,3$ \\
Holandês x Nelore & $6,6 \pm 1,5$ & $9,8 \pm 1,3$ \\
Holandês x Guzerá & $6,9 \pm 1,7$ & $11,1 \pm 0,8$ \\
Holandês x Zebu & $7,3 \pm 1,2$ & $10,3 \pm 1,2$ \\
Média & $7,0 \pm 1,4$ & $10,1 \pm 1,3$ \\
\hline
\end{tabular}

As médias não diferiram estatisticamente pelo teste de Fisher $(\mathrm{P}>0,05)$.

$\mathrm{CV}=20,28 \%$.

Considerando-se que os animais foram bem colostrados, pode-se estimar o volume de colostro ingerido, segundo cálculo de Davis e Drackley (1998). Estes autores consideram ideal uma concentração plasmática de IgG igual ou superior a $10 \mathrm{mg} / \mathrm{mL}$. O volume plasmático do bezerro após nascimento é aproximadamente $6,5 \%$ do peso vivo. Para um bezerro de $36 \mathrm{~kg}$, o volume plasmático seria igual a $2,34 \mathrm{~L}$, e ele precisaria de $23,4 \mathrm{~g}$ de $\mathrm{IgG}$ para obter a concentração plasmática de imunoglobulinas desejada, se a eficiência de absorção fosse de $100 \%$. Considerando-se a eficiência de absorção $25 \%$, a necessidade de imunoglobulinas aumenta para 93,6g. Nesse experimento, foi encontrada concentração média de imunoglobulinas totais no colostro igual a $78,5 \mathrm{mg} / \mathrm{mL}$. Logo, em $78,5 \mathrm{mg} / \mathrm{mL}$ de Ig totais, há $66,7 \mathrm{mg} / \mathrm{mL}$ de $\mathrm{IgG}$, Assim, se o colostro contém $66,7 \mathrm{mg} / \mathrm{mL}$ de IgG e o bezerro precisa ingerir $93,6 \mathrm{~g}$, será necessário 1,4L de colostro para fornecer a IgG necessária.
O volume de colostro ingerido estimado $(1,4 \mathrm{~L})$ é baixo se comparado ao recomendado por Davis e Drackley (2008), de 3,78L. Devido ao fato de os bezerros terem mamado o colostro na vaca, sem controle de qualidade, tempo ou volume, seria esperado que pequena parcela dos animais fossem bem colostrados. Borges et al. (2001) observaram valores de proteína total semelhantes entre bezerros Holandeses que receberam $4 \mathrm{~L}$ de colostro por mamadeira em dois fornecimentos, ou que ingeriram colostro diretamente de suas mães. Já Trotz-Williams et al. (2008) e Beam et al. (2009) relataram associação entre falha na transferência de imunidade passiva e deixar o bezerro mamar o colostro na vaca. No entanto, isto não ocorreu nos animais mestiços $\mathrm{HZ}$ avaliados. Estes são mais leves ao nascer e junto à alta qualidade do colostro, pode explicar a dosagem de proteína total sérica observada acima do ponto de corte para a maioria dos bezerros. Estes dois fatores, junto à alta qualidade do colostro, podem explicar a dosagem de proteína total sérica observada, acima do ponto de corte 
para a maioria dos bezerros. Houve adequada transferência de imunidade passiva sem controle de qualidade do colostro antes da ingestão e de tempo entre nascimento e ingestão. É importante lembrar que há diversas maneiras de garantir adequado fornecimento de imunoglobulinas aos bezerros neonatos. McGuirk (2004) afirma que é fundamental retirar os bezerros da área de maternidade o mais rápido possível, tanto para reduzir o risco de falha na transferência de imunidade passiva quanto a transmissão fecaloral de microrganismos patogênicos.

\section{CONCLUSÕES}

Vacas mestiças Holandês Zebu produzem, em média, colostro de boa qualidade, e não houve efeito de grupo genético da mãe, estação do ano ou sexo do bezerro na qualidade do colostro ou na concentração sérica de proteína total dos bezerros. A ordem de parto das vacas não afetou a qualidade do colostro.

\section{AGRADECIMENTOS}

Os autores agradecem à Fazenda Experimental da Epamig - Felixlândia, pela disponibilização dos animais para o experimento e por toda a ajuda durante sua execução.

\section{REFERÊNCIAS}

BEAM, A.L.; LOMBARD, J.E.; KOPRAL, C.A. et al. Prevalence of passive transfer of immunity in newborn heifer calves and associated management practices in US dairy operations. J. Dairy Sci., v.92, p.3973-3980, 2009.

BESSER, T.E.; SZENCI, O.; GAY, C.C. Decreased colostral immunoglobulin absorption in calves with postnatal respiratory acidosis. J. Am. Vet. Med. Assoc., v.196, p.1239-1243, 1990.

BORGES, A.S.; FEITOSA, F.L.F.; BENESI, F.J. Concentração de proteína total e de suas frações eletroforéticas no soro sanguíneos de bezerros da raça holandesa: Influência da forma de administração e da quantidade de colostro fornecido. Arq. Bras. Med. Vet. Zootec., v.53, p.629-634, 2001.

BUTLER, J.E. Passive immunity and immunoglobulin diversity. In: Proceedings of the IDF seminar: Indigenous Antimicrobial agents of milk - Recent developments. p.14-50, Uppsala, Sweden, 1993.

DAVIS, C.L.; DRACLEY, J.K. The development, nutrition, and management of the young calf. 3.ed. Iowa, USA, 1998. 339p.
DONOVAN, G.A.; BADINGA, L.; COLLIER, R.J. et $a l$. Factors influencing passive transfer in dairy calves. J. Dairy Sci. v.69, p.754-759, 1986.

FLEENOR, W.A.; STOTT, G.H. Hydrometer Test for Estimation of Immunoglobulin Concentration in Bovine Colostrum. J. Dairy. Sci., v.63, p.973-977, 1980.

GODDEN, S. Colostrum management for dairy calves. Vet. Clin. Food. Anim., v.24, p.19-39, 2008.

GULLIKSEN, S.M.; LIE, K.I.; SOLVEROD, L. et al. Risk Factors Associated with Colostrum Quality in Norwegian Dairy Cows. J. Dairy. Sci., v.91, p.704712, 2007.

JAMES, R.E.; POLAN, C.E.; CUMMINS, K.A. Influence of Administered Indigenous Microorganisms on Uptake of [Iodine-125] TGlobulin In Vivo by Intestinal Segments of Neonatal Calves. J. Dairy. Sci., v.64, p.52-61, 1990.

McGUIRK, S.M. Solving Calf Morbidity and Mortality Problems. In: American Association of Bovine Practioners, Preconvention Seminar 7: Dairy Herd Problem Investigation Strategies $36^{\text {th }}$ Annual Conference, 2003.

McGUIRK, S.M.; COLLINS, M. Managing the production, storage, and delivery of colostrum. Vet. Clin. Food. Anim., v.20, p.593-603, 2004.

NAYLOR, J.M.; KRONFELD, D.S. Refractometry as a measure of the immunoglobulin status of the newborn dairy calf: Comparison with the zinc turbidity test and single radial imunodiffusion. Am. J. Vet. Res., v.38, p.1331-1334, 1977.

PRITCHETT, L.C.; GAY, C.C.; BESSER, T.E. et al. Management and production factors influencing immunoglobulin G1 concentration in colostrum form Holstein cows. J. Dairy Sci., v.74, p.2336-2341, 1991.

QUIGLEY, J.D.; MARTIN, K.R.; DOWLEN, H.H. et al. Immunoglobulin Concentration, Specific Gravity, and Nitrogen Fractions of Colostrum from Jersey Cattle. J. Dairy Sci., v.77, p.264-269, 1994.

SISTEMA de análises estatísticas e genéticas - SAEG. Viçosa:UFV, 2000.142p.

STOTT, G.H.; WIERSMA, F.; MENEFEE, B.E. et al. Influence of environment on passive immunity in calves. J. Dairy Sci., v.59, p.1306-1311, 1975.

TROTZ-WILLIAMS, L.A.; LESLIE, K.E.; PEREGRINE, A.S. Passive immunity in Ontario dairy calves and investigations of its association with calf management practices. J. Dairy. Sci., v.91, p.38403849, 2008. 